\title{
LA COMPOSICIÓN DE LOS POEMAS HESIÓDICOS
}

FRANCISCO RODRÍGUEZ ADRADOS

Hesiod organised his poems, specially Theogony and Works and Days, on the basis of preexistent genres: lyrics, cosmogonies and theogonies, genealogies, "instructions" and calendaries. His originality was to create extensive poems introduced by proemia and consisting in a series of blocks. These blocks present a ternary structure $(\mathrm{a}-\mathrm{b}-\mathrm{c})$ and are interconnected by associations. There are also excursus and additions.

\section{GÉNEROS QUE HESÍODO INCORPORÓ}

No queda completo el conocimiento de Hesíodo sin atender a la composición de sus poemas: concretamente, de Teogonía, Trabajos y Días, Catálogo de las Mujeres y Escudo. Independientemente de que estas dos últimas obras sean consideradas, a veces, como ajenas a él. Pensamos que no hay motivo para ello, pero están en su tradición, en todo caso.

En realidad, de la composición de los dos poemas principales nos ocupamos ya en un trabajo aparecido hace años sobre «Las fuentes de Hesíodo y la composición de sus poemas» ${ }^{1}$. El tema central era el de cómo había utilizado Hesíodo sus modelos orientales y griegos para crear poemas de un género nuevo. Esto afecta, necesariamente, tanto al contenido como a los aspectos formales. Yo buscaba más que la continuidad con los modelos, el contraste; y en este contexto presentaba esquemas de composición. Aquí voy, a partir de un cierto momento, a tratar ésta por sí misma, pero es importante señalar antes las

1 Emerita 54, 1986, pp. 1-36. Cf. también «Hesíodo y sus modelos orientales», Anais, Porto Alegre, 1, 1988, pp. 45-49.

EMERITA. Revista de Lingüística y Filología Clásica (EM) - LXIX 2, 2001

pp. $197-223$ 
circunstancias en que Hesíodo se encontró, sus intenciones también. Porque ello determina claramente la composición.

La idea central es la siguiente. La Teogonía es fundamentalmente la expansión de un género oriental que comprendía un proemio (brevísimo) y un poema que unía una cosmogonía y una teogonía; género que por diversos indicios (entre ellos la existencia de un sistema formulario que Hesíodo hereda) fue trasplantado a Grecia en fecha remota, hay huella de él no sólo en Hesíodo, también en Homero. A su vez, Trabajos y Días representa la expansión de otro género, el de las "colecciones de proverbios" que unían parénesis, fábulas, símiles, mitos, máximas. También este género halló derivados en Grecia, antes y después de Hesíodo. Como en ella continuaron viviendo la poesía genealógica y la épica, claros precedentes del Catálogo y el Escudo.

Ahora bien, así como Homero, a partir de la tradición de los pequeños poemas épicos, creó la gran epopeya, así Hesíodo creó la gran Teogonía, que quiere dar una visión tanto histórica como pancrónica del mundo natural y divino. Y la gran obra parenética, Trabajos y Días, que nos ofrece una visión de la totalidad del mundo humano, con intención no sólo descriptiva, sino también parenética, de reforma del mismo. Y el gran Catálogo, que reune todo el universo mítico de Grecia.

Era una tarea nueva y una tarea difícil la de Hesíodo. En lo esencial, lo que hizo fue crear una nueva estructura, formada por dos elementos: a) un proemio, que es un trasunto hexamétrico de proemios líricos diversos y da, por así decirlo, un índice y un anticipo de cada obra; b) un relato formado por bloques sucesivos, organizados bien cronológicamente (Teogonía), bien temáticamente (Trabajos), bien primero temáticamente y dentro de cada uno cronológicamente (Catálogo). Falla en cambio el cierre: los poemas se deshilachan por el final, hay incluso dudas de si esos finales son auténticos.

Pero con esto, como he hecho ver en otra parte ${ }^{2}$, Hesíodo dio el modelo de los escritos filosóficos y científicos que siguieron: piénsese en Parménides o Heráclito o en los tratados hipocráticos y los tratados científicos o eruditos posteriores $^{3}$. Pienso que él, a su vez, siguió el modelo de la lírica griega. Pues

2 «Los géneros literarios griegos», Revista 1616 (Madrid), 1, 1978, p. 163 ss.

3 Sobre los tratados hipocráticos cf. Dolores Lara, Estudio sobre la composición de los tratados hipocráticos, Madrid, 1984. 
los dos proemios de Teogonía y el proemio de Trabajos y Días tienen estructura ternaria: son, ya he dicho, trasuntos hexamétricos de poemas líricos, del canto de las Musas. Pero en su conjunto forman un elemento $a$ en relación con la totalidad de los poemas; $o$, si se quiere, con la parte que les sigue, narrativa y/o parenética, que constituye el elemento $b$. Falta, ciertamente, ya se ha dicho, la conclusión o elemento $c$, habitual en la lírica.

La aportación de Hesíodo a la literatura no ya griega, sino universal, es, pues, decisiva: la organización a base de un prólogo que anticipa una serie de partes o capítulos, está aquí ya. Se ha constituído en un modelo fundamental para el futuro.

Ahora bien, Hesíodo tiene grandes ambiciones, ambiciones por así decirlo unitarias: esas grandes y complexivas descripciones que, además, al menos en el caso de los dos primeros poemas, representan una visión idealizada: el progreso del mundo consiste en la implantación del orden de Zeus, que garantiza la justicia. Pues bien, esas grandes ambiciones no eran fáciles de alcanzar a partir de los precedentes sobre los que trabajaba el poeta, que no son sólo los someramente indicados arriba, sino otros más.

Organizar esos vastos materiales teniendo en cuenta simultáneamente diferentes puntos de vista le llevó a problemas de composición graves. De ellos ha surgido, muchas veces, un cierto escepticismo sobre la posibilidad de establecer una teoría de la composición hesiódica. Han surgido, también, las múltiples teorías analíticas según las cuales tales o cuales partes de un poema no son de Hesíodo, sino de sus imitadores; o son, en el mejor de los casos, una remodelación del propio Hesíodo.

Y también ha surgido la insistencia, en buena medida justificada, en que en Hesíodo encontramos una composición laxa y poco rigurosa ${ }^{4}$, en que hay en ella una lógica débil, una organización por asociaciones más que por clasificaciones ${ }^{5}$. Frente a esta posición encontramos otra: la de W. Nicolai ${ }^{6}$, para el

4 Cf. G. S. Kirk,, «The Structure and aim of the Theogony», en Hésiode et son influence, Vandoeuvres-Génève 1962, pp. 63-95 (la cita en p. 71).

5 Cf. W. J. Verdenius, «Aufbau und Absicht der Erga», ob. cit., pp. 111-159 (cf. sobre todo pp. 119, 156). Sobre las asociaciones, cf. J. A. Fernández Delgado, «Sobre forma y contenido de Los Trabajos y los Días», en Estudios de Forma y Contenido sobre los Géneros Literarios griegos, Cáceres, 1982, pp. 9-29.

6 Hesiods Erga. Beobachtungen zum Aufbau, Heidelberg, 1964. 
cual los Trabajos están organizados en una serie de "bloques" (diecisiete, concretamente) de estructura ternaria, muchos de ellos subdivididos en "células" con análoga estructura. Supongo que los demás poemas también.

En realidad, que hay una composición aproximadamente de este tipo (pero introduciendo la distinción esencial entre proemio y relato) no puede negarse; $\mathrm{y}$ tampoco pueden negarse los procedimientos asociativos dentro de los bloques o para pasar de unos a otros. Ni las digresiones, vueltas atrás, duplicidades, etc. Todo ello deriva de esas circunstancias antes señaladas.

Así, para que el análisis composicional que luego haremos pueda seguirse mejor, preferimos tocar previamente algunos temas cuyo conocimiento es necesario para comprenderlo. Aunque pasaremos rápidamente sobre ellos, porque aquí son sólo un apoyo y su estudio detenido encuentra lugar más adecuado en otros sitios. Son éstos:

a) Problemas de cronología de Homero, Hesíodo y las obras de éste. Problemas de la oralidad.

b) Problemas de autenticidad.

c) Géneros que están en la base de la obra de Hesíodo.

Comencemos por el primer punto. El influjo de Homero en las obras de Hesíodo es innegable: en temas, lenguaje oral, composición. Véase sobre este punto el estudio de R. Janko ${ }^{7}$, así como el de O. Tsagarakis ${ }^{8}$ y la bibliografía que ambos aducen. Por tanto, nada de extraño que los tipos de composición sean semejantes: composición "abierta" a partir del proemio, orden aproximadamente cronológico, pero con digresiones y vueltas atrás, organización por episodios o bloques, intercalación de máximas, símiles, discursos, etc.

En cuanto a las obras de Hesíodo, parece hoy día bien establecido que Teogonía es la más antigua, seguida de Trabajos y Días y del Catálogo, que es una continuación de Teogonía. En el libro de Janko y en Solmsen ${ }^{9}$ se deja claro que la segunda obra presupone la primera (y la tercera también ${ }^{10}$ ). Se complementan: del mundo y los dioses se pasa a los héroes y se pasa al mundo

7 Homer, Hesiod and the Hyms, Cambridge, 1982.

«On the Question of Priority of Homer and Hesiod», Emerita 54, 1986, pp. 189-202.

Hesiod and Aeschylus, Ithaca, Nueva York, 1949, p. 10 ss.

10 Cf. M. L. West, The Hesiodic Catalogue of Women, Oxford, 1985, p. 127 ss. (pero cree que es una continuación de Teogonía, obra de otro autor). 
humano. Nada de extraño que los esquemas composicionales sean semejantes. Es normal que en Trabajos y Días el proemio sea más reducido; es normal que los bloques cronológicos sean sustituídos por otros temáticos.

Otra cuestión es la de la composición oral de los poemas: no voy a entrar en ella. Pero es claro que una serie de rasgos propios de este tipo de composición son comunes a Homero y Hesíodo; y que las fórmulas que el segundo usa son en parte las mismas del primero. Sólo en parte: Hesíodo bebe de una tradición que es parcialmente la misma, parcialmente diferente. En mi trabajo ya citado señalé ${ }^{11}$, siguiendo a otros autores, que hay fórmulas hesiódicas no homéricas, sin duda heredadas, y las hay propias de los Trabajos; también las hay propias de la última parte de esta obra, Los Días $^{12}$. Junto a la literatura oral de tipo épico había, evidentemente, otros géneros que influyeron en Hesíodo.

Antes de entrar en ellos señalemos, sin embargo, que el concepto que nos hagamos de la composición de Hesíodo dependerá estrechísimamente de nuestras ideas sobre la autenticidad de ciertas partes de sus obras. Hay que anticipar que la tendencia general es hoy en el sentido unitario.

Remito una vez más a mi artículo tantas veces citado ${ }^{13}$, así como a A. Martínez Díez ${ }^{14}$. Ya son pura historia aquellas propuestas de Rzach o Jacobson que reducían las obras de Hesíodo a la mitad. Incluso propuestas como la de West de eliminar en Teogonía los episodios de los Gigantes y Cienbrazos o el final y en Trabajos y Días el de los días (el calendario y los trabajos de la navegación serían añadidos secundarios del propio Hesíodo); o las de Kirk de eliminar en la primera obra los temas del Tártaro, Tifón y los héroes hijos de diosas. Son rechazadas las más veces, véase la bibliografía citada; incluso el episodio de Los Días encuentra defensores ${ }^{15}$.

Nosotros partimos, en el análisis que sigue, de una postura unitaria. Las atétesis citadas son indemostrables. En último término, si alguna de ellas fuera cierta, ello no afectaría gran cosa al juicio sobre la totalidad de las obras de He-

11 P. 17 ss.

12 Cf. Fernández Delgado, ob. cit., p. 243 ss.

13 P. 6 ss.

14 «Propuestas para una reordenación de la obra de Hesíodo», en Athlon. Studia grammatica in honorem Francisci R. Adrados, II, Madrid, 1987, pp. 593-601.

15 Cf. A. Pérez Jiménez, «Los 'Días' de Hesíodo: estructura formal y análisis de contenido», Emerita 45, 1977, pp. 105-123; J. A. Fernández Delgado, 1.c. y «Los 'Días' del poema hesiódico: procedimiento de cómputo y poesía oral», en Athlon cit., II, pp. 235-245. 
síodo: haría ver, todo lo más, que la estructura de las mismas permitía naturalmente ampliaciones y digresiones.

En realidad, esas atétesis suelen provenir, igual que las de Homero, de ideas previas que exigen a estos poemas un sistematismo y una organización rígida que no tienen. Si se admite que contienen digresiones para completar su horizonte temático, adiciones, contradicciones, finales deshilachados, etc., deja de haber razón para esas ideas. A estos respectos Hesíodo es semejante a Homero. Es, en realidad, más libre todavía, en cuanto se encuentra ante problemas más graves: introducir en un marco unificado materiales de muy diversas procedencia, de géneros diferentes en realidad.

¿Cuáles son estos géneros? Ya hemos aludido a ellos, pero insistamos todavía.

Hemos apuntado a que los procedimientos de composición oral y el sistema formulario, así como las tradiciones míticas, son parcialmente idénticos a lo que encontramos en Homero, pero sólo parcialmente.

De un lado, en Homero encontramos huellas de la poesía cosmogónica y teogónica: véanse sobre todo los pasajes de los cantos XIV y XV de Ilíada sobre Océano y Tetis como origen de todo, con referencia a la batalla de Zeus y los Titanes y el reparto de poderes entre Zeus y sus hermanos. Hay huellas igualmente de catálogos (el más conocido, el de las Naves en $I l$. II) y de genealogías, las más sobre base femenina: no sólo la de $O d$. XI, son muy frecuentes referencias genealógicas a partir de un personaje femenino con fórmulas coincidentes con las de Hesíodo ${ }^{16}$. Y hay el uso de los mitos (no de las fábulas) con fines de parénesis, así como abundancia de máximas.

De otro lado, como ya se ha dicho, en Hesíodo aparecen numerosos elementos épicos. Y no sólo en las fórmulas y en las características generales de la composición oral, ni en el uso de la digresión, la vuelta atrás, etc. La Teogonía y el Catálogo están llenos de digresiones de corte épico, de una "épica divina" en realidad: piénsese en el nacimiento de Afrodita, la castración de Crono, el nacimiento de Zeus, el episodio de Tifeo, el concurso para la elección del marido de Helena; Trabajos y Días ofrece menos oportunidad, pero mitos como el de Prometeo son de corte épico, también. Cierto que poemas orientales como el triunfo final de Marduk en el Enuma Elish ofrecían un

16 Cf. mi art. cit., p. 19. 
modelo: pero es la existencia de la épica griega la que explica los desarrollos hesiódicos.

Después de esto, hemos de insistir en los modelos que sigue Hesíodo. Dejando aparte la poesía épica, los encontramos de origen oriental, aunque pensamos que conocidos a través de derivaciones griegas: y ello porque a) existen sistemas formularios propios de ellos y b) existen en Grecia misma derivaciones independientes de Hesíodo. Esto no quiere decir que no hayan confluído, en Grecia, con géneros griegos originales. Hay otros géneros para los que es menos necesario buscar modelos orientales. En fin, prescindiendo del origen remoto, encontramos, aparte de la épica, los siguientes géneros que Hesíodo incorporó a su obra:

1. La lírica. Es la lírica griega, cantada con frecuencia como proemio antes de un relato épico: aparte de que es habitual que una composición lírica comience con una parte inicial o proemio que anticipa el tema del canto ${ }^{17}$. Hesíodo no ha hecho sino incorporar el proemio a su poema, convirtiéndolo en hexamétrico, como ya Homero había convertido en hexamétricos otros poemas líricos (los trenos en honor de Héctor, por ej., en el canto XXIV de $I l$. . $^{18}$. Hesíodo era un aoidós, un 'cantor', término que abraza épica y lírica; en los Juegos fúnebres en honor de Anfidamante, en Cálcide, en que intervino ( $O p .654$ ss.), había sin duda lírica trenética.

No le debió de ser difícil, pues, a Hesíodo llegar a esa síntesis, teniendo en cuenta, de otra parte, que algunos poemas orientales tenían ya un mínimo proemio. Así el Canto de Ullikummi comienza: "Al dios...a Kumarbi voy a cantar". Y el Gilgamés: "Voy a entonarle un canto de alabanza a Gilgamés, el héroe".

2. Las cosmogonías-teogonías. Este es el género oriental que conocemos a través de textos diversos (hetitas, hurritas, babilonios, canaanitas, etc.) y que se está hoy de acuerdo en que está en la base de la Teogonía hesiódica. He propuesto que variantes diversas de estos poemas se trasmitían oralmente en griego antes de Hesíodo; han dejado huella no sólo en Homero, también, luego, en Museo, Epiménides, los órficos, Ferécides, Alcmán, etc. Lo esencial es esto: el modelo no es un poema concreto, en la Teogonía hay huellas de formulaciones diversas y contradictorias sobre los orígenes del mundo ${ }^{19}$.

17 Cf. mis Orígenes de la lírica griega, Madrid, Coloquio, $1986^{2}$, pp.56 ss., 59 ss., 112 ss., 149 ss.; y Fiesta, Comedia y Tragedia, $2^{\mathrm{a}}$ ed., Madrid, 1983, p. 116 ss., etc.

18 Cf. más ejemplos y detalles en Orígenes cit., p. 49 ss.

19 Cf. mi trabajo, p. 13 ss. También F. Solmsen, «The two Near Eastern Sources of Hesiod», Hermes 107, 1989, pp. 413-422 (que reduce los modelos a dos, en realidad son muchos más). 
El problema de Hesíodo está precisamente en combinar tradiciones muy diferentes (si lo más antiguo es el Agua o la Oscuridad o el Huevo Cósmico, etc., si hay un modelo sexual o no, etc.) y combinarlas con la religión "femenina" que pone a Gea o Rea en el origen del mundo. Esto lleva a problemas muy graves de composición. Por otra parte, estos poemas, como ya dijimos, ofrecían la posibilidad de insertar episodios épicos.

3. Las genealogías. Sobre su presencia en Grecia desde Homero y antes ya he hablado. Era un género difundido en Beocia y que tuvo vitalidad después de Hesíodo, quien no hizo sino apropiárselo ${ }^{20}$. Evidentemente, admitía desde siempre contaminaciones con la épica, como también es verdad la inversa. Por otra parte, es claro que en los poemas cosmológico-teogónicos había ya un inicio de poesía genealógica. Y la poesía genealógica griega, referida a las familias de los fundadores de estirpes y pueblos, hizo que Hesíodo desarrollara el modelo, dentro de la Teogonía y a continuación de ella (en el Catálogo). Son muy característicamente griegas las "genealogías femeninas" a que he aludido.

4. Es bien conocida la poesía oriental de "consejos" o "instrucciones" y de "proverbios: en Mesopotamia desde la época sumeria, en pleno III milenio, a la asiria (el Ahikar); en Egipto también desde el III milenio. No doy aquí el detalle, dí datos en mi anterior trabajo. Lo importante es que el modelo en que un rey o secretario aconseja a un hijo o discípulo y aquel otro en que se trata de máximas de tipo general, son variantes de uno mismo y hallan reflejo, ambos, en Hesíodo (Trabajos y Días). Y que incluyen fábulas y mitos de valor didáctico (como igualmente Hesíodo).

También esta poesía estaba difundida en Grecia antes de Hesíodo, basta ver su eco en Homero; y continuó independientemente, tras él, en Teognis, Solón, Focílides, Isócrates, etc. ${ }^{21}$

5. También tienen tradición los "calendarios" y "los días", que en realidad son variantes del catálogo: lo mismo en Mesopotamia que en Egipto, también sin duda, a juzgar por la existencia de fórmulas propias, en $\mathrm{Grecia}^{22}$.

Estos son los géneros que Hesíodo combina para crear poemas con organización binaria, según se ha dicho: ya sobre el esquema del poema cosmo-

20 Cf. M. L. West, ob. cit., p. 3 ss., también G. S. Kirk, art. cit., p. 69 s.

${ }^{21}$ Cf. Fernández Delgado, «Sobre forma y contenido...» cit., p. 11 s. También M. Erren, «Die Anredestruktur im archaischen Lehrgedicht», en W. Kullmann-M. Reichel (eds.), Der Uebergang von der Mündlichkeit zur Literatur bei den Griechen, Tubinga, 1990, pp. 185-197.

22 Cf. P. Walcot, Hesiod and the Near East, Cardiff, 1966, pp. 93 ss., 101 ss.; J. A. Fernández Delgado, «Los Días...» cit., p. 243 ss. 
lógico-genealógico, ya sobre el de enseñanza y parénesis, ya sobre el catálogo. Pero ampliando, incorporando elementos, buscando crear una unidad, una descripción total del mundo divino y humano. Todo ello, sin olvidar las técnicas orales ni los modelos épicos e incurriendo, cómo no, en composiciones desequilibradas o puramente asociativas. El resultado es la invención, en Grecia, de la poesía didáctica, la que explica lo que siempre ha sido, lo que es y lo que debe ser.

\section{ANÁLISIS DE LA COMPOSICIÓN DE LOS POEMAS}

\section{La Teogonía.}

La descripción del mundo divino, que es al tiempo natural (Tierra, Cielo, Mares, Tártaro, etc.), se hace narrando cómo surgió y evolucionó: es el complejo de cosmogonía + teogonía de que hemos hablado, continuado luego por el mundo de los héroes que nacieron de diosas y hombres y (si el Catálogo es realmente una continuación de la Teogonía), el de los que nacieron de dioses y mujeres. Este es el cuerpo de la Teogonía (116-1018), pero va precedido, como también se ha dicho, por el proemio o conjunto de proemios (versos 1-115).

Y va seguido, en el texto que se nos ha transmitido, por un epílogo (10191022) que se refiere, en realidad, tan solo a las diosas que se unieron a mortales y anuncia el tema de las mujeres que se unieron a dioses (el tema del Catálogo). Es fácil darse cuenta de que este no es un epílogo normal: o bien, como se ha propuesto, el final del poema es aditicio y se ha perdido el antiguo cierre tras celebrarse el nacimiento de los hijos de Zeus y las hazañas de Héracles (955); o bien es un elemento de transición, si el Catálogo (cuyo comienzo nos ha trasmitido el POxy. 2354 comenzando por esos versos 1021-1022) formaba cuerpo con nuestra obra.

Vamos a estudiar, pues, sucesivamente, el proemio (I) y el cuerpo del poema (II).

\section{El Proemio.}

Insisto en la descripción del proemio como una versión hexamétrica de dos proemios líricos que celebran a las Musas y su canto y, en la descripción de éste, dan por decirlo así un anticipo o índice del cuerpo del poema que va a seguir. $\mathrm{O}$ 
sea: la poesía didáctica, en su versión cosmogónico-teogónica a que pertenece nuestro poema, surge sobre el modelo del complejo proemio lírico + poema épico.

Los dos proemios tienen estructura lírica, ternaria: son celebraciones de las Musas, con un centro que indica sus mitos, sus excelencias y su canto y un epílogo que vuelve a celebrarlas: hay, pues, elementos $a, b$ y $c$, aunque, juntos los dos proemios, constituyan un elemento $a$ para el poema entero. Otro elemento lírico es la referencia al propio poeta, como era habitual en la lírica: ya, en el primer proemio, en el epílogo c (22 ss.: iniciación poética de Hesíodo, las Musas le invitan al canto ${ }^{23}$ ); ya, en el segundo, en un apéndice al elemento $b$ (94 ss.) y en el epílogo ( $c, 104$ ss.), en que Hesíodo habla del canto del aedo e invita a las diosas a que le concedan a él el canto y a que canten ellas: anuncia, en definitiva el poema que sigue.

Dentro del esquema lírico, el recurso de Hesíodo para convertir los proemios en anticipos o índices es doble: a) al presentar ya en relato ya en cita directa el canto de las Musas, indica simultáneamente el contenido del poema; b) en las referencias a su propio canto, hace lo mismo.

El esquema es complicado, lo resumimos:

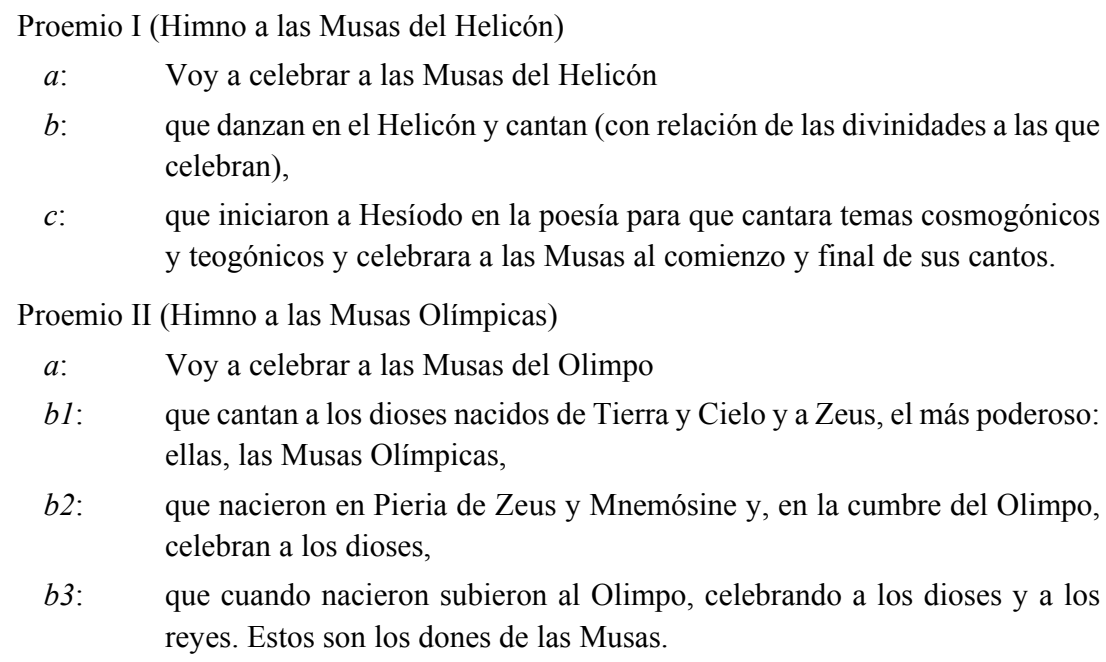

b3: $\quad$ que cuando nacieron subieron al Olimpo, celebrando a los dioses y a los reyes. Estos son los dones de las Musas.

23 Sobre este tema, cf. G. Arrighetti, «Esiodo e le Muse: il dono della verità e la conquista della parola», Athenaeum 80, 1992, pp. 45-63 (con bibliografía). 
b4 (apéndice): Pues de las Musas vienen los aedos, que celebran a los héroes y dioses, alegran a las gentes.

$c$ : $\quad$ Adiós, Musas, dadme voz para celebrar a los dioses nacidos de Tierra y Cielo, decidme qué nació primero.

Como se ve, los elementos líricos son claros: estructura ternaria, anillos (Ringkomposition) en honor de las Musas, centros introducidos por el relativo y elogiosos para las Musas, referencia al poeta a la manera de la sphragís o "sello" de los líricos. También el enlace del final, v. 115, con lo que va a seguir: 116 "primero nació el Caos..." Lo nuevo es, fundamentalmente, ya se ha dicho, cómo ha sido incrustado el "índice" dentro de los dos proemios: al celebrar a las Musas, dan compendios del canto de las Musas. Pero prestemos atención a cómo los recursos de la composición épica, que subyace a toda la nueva narrativa, se han abierto paso también:

a) Hay una duplicación: proemios a las Musas del Helicón (las más próximas al poeta, nacido en Ascra, al pie del monte) y a las Olímpicas (las más próximas a Zeus). La conexión es laxa (v. 35: "¿pero por qué digo esto acerca de la encina o la roca?”. Es decir: pasemos a las Musas que más de cerca atañen a Zeus).

b) Hay multiplicación de los centros en el Proemio II, hay en éste un apéndice. Hay en el I un epílogo que es, en parte, un apéndice del mismo tipo: mezcla de elementos poco lírica. Hay, al final de II $b 1$, un epílogo "fallido", con mención de las Musas.

c) Los cantos de las Musas están fragmentados entre los diversos elementos $b$ y $c$, incluída la fragmentación de los "sellos". El resultado es bastante incoherente: el o los "índices" de Teogonía y de la futura labor poética de Hesíodo no coinciden exactamente ${ }^{24}$.

Efectivamente, I $b$ contiene una especie de "índice inverso" de Teogonía, que comienza por Zeus y termina por Tierra y Cielo, índice por lo demás incompleto y con ciertas peculiaridades propias: Hera es "argiva", Afrodita parece una simple hija de Zeus. Sin duda, el empezar por éste es para darle honor. En cambio, el "índice" de 45 ss. (en II $b 1$ ) empieza por Tierra y Cielo, aunque pasa a dar honor a Zeus y referirse, finalmente, a los hombres. En $b 2$ hay una referencia genérica a los dioses y en $b 3$ se pasa especialmente a Zeus y luego a los reyes y en $b 4$ a los aedos. II $c$ da una especie de resumen: celebración de los dioses nacidos de Tierra y Cielo hasta los Olímpicos.

24 Cf. sobre esto J. Strauss Clay, «What the Muses sang: Theogony 1-115», GRBS 29, 1998, pp. 323-333. 
Para lograr este cuadro complejo Hesíodo ha duplicado los lugares (Helicón, Olimpo), momentos (cima del Olimpo, subida al mismo, pasajes generalizantes), se ha referido ya directamente al canto de las Musas, ya a través del que inspiran a Hesíodo. Ha logrado destacar ya la antigüedad de los primeros dioses, ya el poder de Zeus. Y se ha referido, también, a los reyes, los aedos y los hombres en general.

No puede ocultarse la existencia de una tensión creciente del proemio I al II, más extenso y en que se termina con la referencia más directa y exacta al poema que sigue.

Es notable que los pasajes que se refieren a Hesíodo (32 ss., 104 ss.) aluden tan sólo a los dioses primordiales y a los olímpicos, que son aquellos a quienes se dirige el poema. Las Musas, en cambio, tienen temas de canto más amplios: ¿se alude a Trabajos y Días, en que tan gran papel desempeñan reyes, aedos, hombres? ¿O para éstos al menos se piensa en el final de Teogonía, incluído el Catálogo?

Estas duplicaciones, discordancias, lagunas y dudas dentro de los proemios son características del género didáctico, incluso en una época avanzada como es la de los escritos hipocráticos. El esquema de "composición abierta", tomado de la épica, único existente en la época en realidad, ha permitido volver sobre el tema, matizar, poner los acentos. Pero tiene, a nuestros ojos, estos defectos.

\section{El cuerpo del poema (116-1018).}

El discurso de la narración avanza, como se ha dicho, en orden en principio cronológico, aunque su intención es pancrónica puesto que a) son pancrónicas y omnipresentes las divinidades primordiales o naturales (Tierra, Cielo, Montes, Amor...); b) es, a partir de un cierto momento, omnipresente el poder y la inteligencia de Zeus, que simboliza la edad humana. Así, se sigue paso a paso el nacimiento de las sucesivas divinidades primordiales, de los Titanes, Crono, Zeus, los Olímpicos, los hombres nacidos de las diosas. Se pasa, en definitiva, de la cosmogonía a la teogonía.

Pero, como en la épica, que es la que ha suministrado el modelo para la ampliación del esquema cosmogónico-teogónico y del genealógico, existen problemas para una cronología estricta. Aquí son más graves. Son éstos: 
a) La narración cronológica se interrumpe para excursos considerados importantes por su trascendencia general: castración de Urano y victoria de Crono, con el nacimiento de Afrodita (154-206); himno a Hécate (411-452); nacimiento de Zeus, su victoria sobre Crono y sobre Prometeo y los Titanes (453-735); descripción del Tártaro (736-819); victoria sobre el monstruo Tifeo (820-880).

Son episodios destinados a magnificar la línea de Urano: primero a Crono, luego y sobre todo a Zeus. En cuanto a la descripción del Tártaro, completa la visión general del mundo. Por lo demás, estos elementos no son más que versiones ampliadas de los pequeños mitos que se narran a propósito de tal o cual deidad. En uno y otro caso, son en principio adiciones ligada por un $\delta \varepsilon ́$ y más o menos expandidas.

b) Otras veces, simplemente, el orden cronológico no puede seguirse por una serie de razones. Los tema del incesto o de los nuevos hijos de los dioses más antiguos, sea por uniones entre sí sea automáticamente, hacen intervenir a veces a personajes que ya parecían desaparecidos (así Tierra, madre de Tifeo) y unen generaciones distantes. Las líneas colaterales, si se quieren tratar de por sí, hacen descender a generaciones recientes y luego hay que retroceder para repescar las antiguas.

c) Por otra parte, como ya se ha dicho, Hesíodo tiene que compaginar tradiciones cosmogónicas diferentes, lo que lleva a incoherencias.

Ha tratado, sin embargo, de solucionar, al menos parcialmente, estos problemas mediante sus tratamientos característicos: el establecimiento de "bloques" con una cierta unidad temática, con tendencia a la organización ternaria y con una cierta lógica en su ensamblamiento y en su organización interna. Aunque con frecuencia es una lógica puramente asociativa, que también aparece en la inserción de excursos como los citados: por ejemplo, el del Tártaro es introducido porque fue allí donde fueron arrojados los Titanes vencidos.

Vamos a dar un repaso a los bloques, uno a uno.

\section{Bloque I (136-210).}

Carece de elemento $a$ : los dos proemios hacen esta función, además de referirse a la totalidad del poema. El elemento $b$ comprende los sucesivos nacimientos que van del de Caos al de los Titanes, incluído Crono, y el de Afrodita, concluído con una referencia al amor humano: hay un cierto anillo por la aparición de Eros al comienzo y final del bloque (es hijo de Caos, 120; acompaña a Afrodita, 201). El elemento $c$ o epílogo consiste en las amenazas 
de Urano contra sus hijos los Titanes: perecerán por sus maldades, lo que es un anuncio del Bloque II y del triunfo de Zeus.

El bloque, iniciado por los dioses más antiguos (Caos, sus hijos Tierra, Tártaro y Eros, descendencia de Caos), continúa con la descendencia de Tierra por sí misma o por obra de su hijo Cielo, con el que engendra a los Titanes, incluído Crono, y Titánidas. Esta se revelará la línea principal. Pero hasta que llegue al centro de la escena, Hesíodo ha de dejar lugar para otros descendientes antiguos de Tierra o de Tierra / Cielo: los Cíclopes y Cienbrazos, que se revelarán en su momento como auxiliares de Zeus: es erróneo atetizarlos, aunque ello daría mayor coherencia al poema ${ }^{25}$.

Luego sigue un momento clave: el primer episodio del mito de la sucesión, con la castración de Cielo, el triunfo de Crono y el nacimiento de Afrodita, que es simbólico para el futuro de la raza humana, como Eros al comienzo.

En él se vuelve sobre los nuevos hijos de Tierra y Cielo, odiosos a su padre, los Titanes, que figuran en un nuevo apartado (desde $154 \mathrm{ss}$.) encabezado por

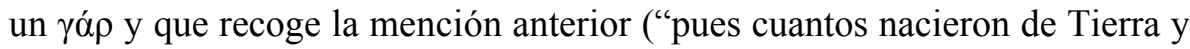
Cielo..."). Sigue el mito de la castración de Crono y el nacimiento de Afrodita, ya referido, que es el clímax del bloque, terminado a continuación por el epílogo o elemento $c$.

Tenemos, pues, una serie de unidades genealógicas que poco a poco nos van conduciendo a la línea central del poema, la línea Tierra / Cielo - Crono - Zeus y que culminan en el mito referido y el epílogo, que anticipa el castigo de los Titanes en II.

Nótese que las unidades genealógicas van en aposición y son ampliables: Hesíodo o un continuador han podido introducir otras sin variar el principio de la composición. Están organizadas en unidades referentes a nacimientos o grupos de nacimientos: primero el de Caos, luego el de Tierra, Tártaro y Eros, luego el de los hijos de Caos. Siguen varios grupos de hijos de Tierra.

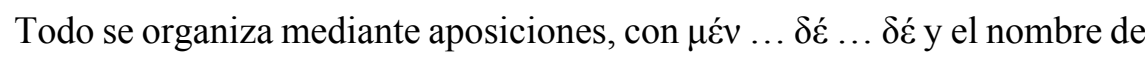
una divinidad, Caos o Tierra, en cabeza. Nótese que toda esta genealogía suministra una descripción de la tierra y el ambiente que la rodea (Amor, Noche, Día ..., Cielo, Montes, Ponto, Océano): culmina con los Titanes, que ya no son dioses "naturales".

25 Cf. «Las fuentes de Hesíodo...» cit., p. 7. 
Y ahí ya interviene el primer episodio del mito de sucesión: se pasa de la cosmogonía a la teogonía. Hay que hacer notar, a este respecto, que desde el punto de vista de la composición este episodio consiste simplemente en una "ampliación" del nacimiento de los Titanes y concretamente de Crono, odioso a su padre. Dentro del mito, el nacimiento de Afrodita no es sino una continuación, unida al tema de la castración con un simple $\delta \varepsilon ́$.

Bloque II (211-885).

Considero hoy que de aquí a la victoria de Zeus hay solamente un bloque, cuya primera parte constituye en realidad un apéndice o digresión que se aparta (como ya se apartaba, al final de II, el nacimiento de Afrodita) de la línea principal, que es luego recuperada. En cierto modo, hace pendant al comienzo de I, también ajeno a la línea principal, la de los Titanes y Zeus. Consiste, también, en una serie de unidades que comienzan con el nombre de una diosa o dios y un $\delta \varepsilon ́$, para culminar todo en una serie de mitos (los del nacimiento y triunfo de Zeus, en este caso) y un epílogo $c$ (881-885): insiste en la derrota de los Titanes y en el triunfo de Zeus, hace eco, pues, al epílogo de I.

Hay, pues, paralelismo entre I y II, más extenso. Ambos bloques pasan de las líneas ajenas a la de Tierra / Cielo a esta última y, dentro de ésta, a la de Crono y Zeus; ambos pasan de unidades genealógicas en aposición a relatos de los dos momentos del mito de sucesión; ambos culminan en la victoria de Zeus, primero presagiada, luego realizada. El alejamiento de la línea central al final de I y comienzo de II es recuperado dentro de este bloque.

El bloque II está dedicado, primero, como digo, a recoger ramas laterales diferentes de la de los Titanes, hijos de Tierra y Cielo. Las sucesivas unidades (multiplicables y susceptibles de adiciones sin romper el principio composicional) se refieren

a) a los hijos de Noche (hija de Caos y Erebo) y de su hija Eris (211-232).

b) a los hijos de Ponto (hijo de Tierra sin unión sexual) y su madre Tierra, a saber, Nereo, Taumante, Forcis, Ceto y Euribia (233-335). A Nereo, a Taumante y a Ceto unida a Forcis se les atribuyen unidades independientes, la de Ceto y Forcis provista de apéndices (algunos atetizados a veces) y concluída con un epílogo parcial (333336).

c) a los hijos de Tetis y Océano, hijos ambos de Tierra y Cielo, que engendran los ríos (337-370). 
Así, haciendo en este momento un inciso, primero se describe la rama de Caos, a través de su hija Noche, luego, la de Tierra unida a Ponto, finalmente la de Tetis y Océano. Con unión sexual, a veces incestuosa, o sin ella nacen hijos en ocasiones monstruosos. Hay, como al comienzo de I, una descripción del mundo. Con esto quedan apartadas ramas laterales y personajes monstruosos y el camino queda despejado para volver a la descendencia de Tierra y Cielo que es central: a los Titanes y, entre ellos, a Crono.

El procedimiento es puramente yuxtapositivo. Pero así como el nacimiento de Afrodita, al final de I, permitía el paso a las líneas ajenas a la de Tierra / Cielo, así en II se retorna a la línea de Tierra / Cielo a través de la descendencia de Océano y Tetis, hijos de ambos. Ese paso es gradual, no marcado formalmente, sólo por la confluencia de los contenidos.

Así, tanto en I como en II de un comienzo de dioses primordiales, de nacimientos sin unión sexual, de religión femenina en que dominan las uniones de las mujeres y, concretamente, de Tierra (lo que he interpretado como una aportación helénica a las cosmogonías orientales conocidas), de dioses naturales y monstruosos, se ha pasado a un nuevo panorama: el del principio patrilineal, con una progresiva humanización. Se da preferencia a los hijos de Urano y, de entre ellos, a los Titanes, de entre ellos a Crono y luego a Zeus. En una palabra: se pasa, como ya dije, de una cosmogonía a una teogonía.

Con esto cerramos el inciso. Sigue luego

d) Relación de los Titanes, que culmina en el himno a Hécate, hija de Asteria, a su vez hija de la Titánide Febe (371-452). Introduce una ventana que mira a los hombres, como Afrodita en I: favorece a los reyes justos y a los pueblos. Es una unidad en principio como las demás, pero una unidad "ampliada" con el mito.

e) Nacimiento de Rea, de la que nace Zeus. Aquí interviene una "ampliación" relativa a su nacimiento y toda la serie de mitos que ya sabemos. Se encadenan a él (453-880) mediante simples $\delta \varepsilon ́$, salvo la descripción del Tártaro, que completa la del mundo.

Todo culmina, ya se ha dicho, en la gloria de Zeus y en el epílogo que la celebra (881-885): Zeus reparte las prerrogativas entre los dioses, se establece como soberano.

Se habrá visto que ambos bloques siguen estructuras paralelas, siendo el segundo más extenso y llevando más lejos el tema del triunfo de la descen- 
dencia de Tierra / Cielo y, concretamente, de Zeus. Es el verdadero tema del poema, ya anunciado desde los proemios.

Todo esto está llevado a cabo mediante un procedimiento que es simétrico en los proemios y en el cuerpo del poema. Hay dos proemios, el segundo de los cuales, más extenso, lleva más lejos el primero; dos bloques, ambos culminando en el tema central tras unos comienzos ajenos a él que recogen otros materiales, pero llevando más lejos el segundo los planteamientos del primero.

El segundo proemio lleva a su clímax al primero, el segundo bloque lleva a su climax al primero y a todo el poema. Los procedimientos son siempre acumulativos y de "ampliación", apoyados uno y otro en la epopeya. También puede aludirse a ésta para explicar la insistencia en el tema decisivo en la parte final por oposición a la anterior, piénsese en la Ilíada; incluso la organización en dos escalones de tensión creciente, piénsese en la Odisea. Y para explicar el anticlimax en que termina el poema.

Este anticlimax está constituído por los bloques que siguen.

Bloque III (886-962).

Consta de una serie de unidades, puramente apuestas mediante un $\delta \dot{\varepsilon}$ y relativas a las distintas esposas de Zeus. Es, evidentemente, el complemento de su gloria, al tiempo que la narración del nacimiento de diversos dioses y héroes, anunciado en los proemios. No hay proemio: es suficiente el epílogo de II, como el de I es suficiente para el comienzo de II. En cuanto a epílogo, se ha propuesto que podría estar en 950-955, tema de la gloria de Héracles, hijo de Zeus y su apoteosis. Sería, además, el cierre del poema.

Pero esta es sólo una hipótesis: en nuestro texto sigue la descendencia de Helios y Perseis. Y sigue, también lo hemos dicho, la relación de las diosas que, unidas a mortales, engendraron héroes.

\section{Bloque IV (963-1018).}

Es la referida lista de las diosas que engendraron héroes, construída apositivamente, mediante el repetido $\delta \varepsilon ́$. Si es auténtica, no hace otra cosa que completar el poblamiento del mundo, pasando de los dioses a los héroes. La genealogía se cierra, ya lo dijimos, con un epílogo 1019-1022 que, a su vez, abre el Catálogo de las Mujeres. Este completa el cuadro de los héroes como pendant 
al catálogo anterior: ahora se trata de los que son hijos de dioses y mujeres mortales.

En todo caso, desde el punto de vista de la cosmogonía y teogonía que culminan en Zeus, todo esto es puro anticlimax, construido apositivamente y sin "ampliaciones" ni mitos. Bastante próximo, de otra parte, a lo que sucede en Trabajos y Días y al deshilachamiento o apertura final de diversas muestras del género didáctico en los siglos posteriores.

\section{Trabajos y Días.}

La composición de esta obra tiene rasgos aproximados a los de Teogonía, de la cual constituye una especie de segunda parte, posiblemente anunciada, como dijimos, en su proemio. La completa dando un panorama del mundo humano; y ciertos episodios, como el de las dos Erides y el de Prometeo, son una reelaboración de los correspondientes de Teogonía.

Parece, pues, lógico considerar que también la composición es una imitación. Es, ya decimos, un poema paralelo, organizado también él mediante un proemio y un cuerpo del poema, éste consistente en diversos bloques apuestos, procedentes de géneros preexistentes y con tendencia a la estructura ternaria. Admiten, claro está, expansiones (apéndices), duplicaciones, etc. y se enlazan asociativamente. Trabajos y Días es también un "gran poema", una gran síntesis: en este caso, de la reflexión sobre el hombre. La organización es, así, menos clara que en Teogonía.

Hay, por fuerza, grandes diferencias. La organización de los bloques no puede ser cronológica, aunque sí lo es la organización interna de los dos calendarios (el de las labores agrícolas y el de la navegación) y la parte de "Los Días". El elemento de relato es reducido, está sobre todo en los mitos y la fábula iniciales, también en algunos excursos. En cambio, es muy importante el elemento parenético, sobre todo en los elementos $c$. Pero es muy frecuente que estos elementos se expandan mediante mitos o relatos: suman, así, la función $c$ con la función $a$ del mito siguiente, se convierten en elementos de transición.

Hay que hacer notar que Hesíodo ha introducido importantes modificaciones en sus modelos, que son como sabe el lector de este trabajo las colecciones de proverbios y los "consejos", de origen oriental pero sin duda difundidos en 
Grecia. En principio los proverbios o máximas tienen un destinatario general, los "consejos" son dirigidos bien a un rey, bien a otra persona concreta, habitualmente el hijo del rey. Pues bien, los Trabajos son en principio una exhortación a Perses, hermano del poeta, a que se comporte con justicia para evitar el castigo de Zeus; y a que trabaje, única manera de poder vivir con justicia.

Pero sucede que la exhortación a Perses se mezcla con exhortaciones a los reyes y sobre todo, a partir de un cierto momento, con máximas de destinatario general, como las de las colecciones de proverbios. Hesíodo puede introducir así largas series de máximas; y puede introducir, también, los calendarios, que especifican los trabajos que hay que realizar a lo largo del año.

Vemos, pues, la mezcla de géneros y la combinación de géneros que Hesíodo introduce al servicio de este género nuevo, que los desborda y comprende a todos. Pero, además, las colecciones de "consejos" y "proverbios", lo mismo en Mesopotamia que en Egipto, incluían, como se ha dicho, fábulas, símiles y mitos. Pues bien, Hesíodo ha introducido una clasificación: ha colocado en cabeza las fábulas y mitos, luego los consejos y máximas. A los primeros les ha dado, según era habitual en Grecia, una estructura ternaria ${ }^{26}$.

Hay que decir que, sin duda alguna, Hesíodo operó no sólo sobre modelos orientales y las versiones griegas que de ellos circulaban, caracterizadas por un lenguaje formulario propio ${ }^{27}$, sino también sobre modelos propiamente griegos, bien épicos (recuérdese la presencia en Homero de mitos-ejemplo), bien, sin duda, por lo que respecta a la fábula, procedentes de la fiesta y el banquete.

Más todavía que en la Teogonía, Hesíodo ha debido realizar una importante labor sumando modelos, contaminándolos o adicionándolos, clasificándolos, siempre al servicio de la creación de un gran poema didáctico. Poema que fue por siempre una cumbre de la poesía griega: hubo luego, sí, poemas didácticos, pero no de esta extensión y ambición.

Veamos pues, sucesivamente, los diferentes elementos de que consta.

26 Sobre la estructura de la fábula, cf. mi Historia de la Fábula Greco-Latina, I, Madrid, 1979, pp. 43 ss., 381 ss. y «La fábula griega como género literario», en Estudios de forma y contenido sobre los géneros literarios griegos cit., pp. 33-46. Sobre fábula y mito y sobre la estructura de ambos en la lírica, mi artículo «Mito y fábula», EMERITA 61, 1993, pp. 1-14, y mis Orígenes de la Lírica griega cit., pp. 158 ss., 208 ss.

27 Cf.«Las fuentes de Hesíodo...» cit., p. 21. 
1. Proemio (1-10).

Es, en realidad, una versión abreviada de los dos proemios de Teogonía: se refiere exclusivamente a Zeus y su poder justiciero sobre los hombres. Se abre con una invocación a las Musas $(a)$ y se cierra con una exhortación a Zeus a aplicar sus leyes conforme a la Justicia y con un anuncio de que va a decir algunas verdades a su hermano Perses, que ha abusado de Hesíodo en el reparto de la herencia paterna:

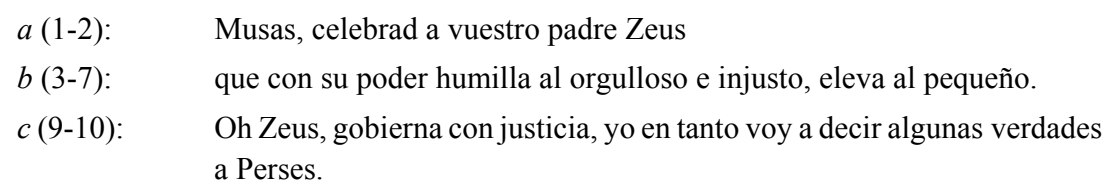

\section{Cuerpo del poema (11-828)}

Bloque I (11-41).

Tema de las dos Erides, que nosotros traduciríamos por Discordia y Emulación y que Hesíodo introduce aquí rectificando el mito de Teogonía 225 ss. $\mathrm{Al}$ ir tras el proemio inicial, no precisa de elemento $a$ : sólo tienen el $b$ (11-26), mito de la Eris buena y la mala, y el $c(27-41)$, exhortación a Perses a seguir la Eris buena y resolver las diferencias con su hermano.

Bloque II (42-105).

Enlaza con el final de I ("no saben cuánto más es la mitad que el todo y cuán-

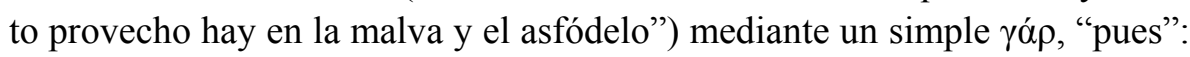
Zeus ha escondido a los mortales los recursos de vida como castigo por los engaños de Prometeo y Pandora. No hay, pues, $a$, todo es un largo relato mítico (b), terminado por un brevísimo epílogo $c$ (105): "así, no es posible escapar de la mente de Zeus". Los hombres viven ahora desgraciados y Perses hará bien, se entiende, en no intentar engañar a Zeus comportándose injustamente.

Bloque III (106-201).

Tercer mito, con extensión creciente y organización clara $a b$, que pasa insensiblemente al elemento epilogal $c$ : mito de las edades del mundo, traído asociativamente por la referencia en el mito anterior a las desgracias de los 
hombres, que son "explicadas" ahora de una manera diferente:

$\begin{array}{ll}a(106-108): & \text { Si quieres, voy a contarte otro mito. } \\ b(109-173): & \text { Relato de las edades sucesivas, de oro, plata, bronce, de los héroes, } \\ & \text { con felicidad decreciente para los hombres. } \\ b-c(174-201): \quad & \text { La referencia a la quinta y más detestable edad, la de hierro, la } \\ & \text { actual, comienza con un "iojalá no hubiese yo nacido entre los } \\ & \text { quintos hombres!” El relato mítico es sustituído por una descripción } \\ & \text { del estado desgraciado del mundo en nuestros días, lo que no hace } \\ & \text { sino confirmar lo que antes se explicó con ayuda de los mitos de } \\ & \text { Prometeo y Pandora. Los elementos } b \text { y } c \text { aparecen fundidos y hay } \\ & \text { insistencia sobre las conclusiones obtenidas de los mitos anteriores. }\end{array}$

\section{Bloque IV (202-285).}

Hay aquí un conglomerado de mitos y parénesis en el cual los elementos $c$ de una unidad funcionan simultáneamente como elemento $a$ de la siguiente: nuevo procedimiento de invención hesiódica. Podrían, ciertamente, establecerse tres bloques en torno, sucesivamente, a los temas del ruiseñor, el Juramento y la Justicia, pero la fusión de los elementos $c$ y $a$ y la nueva referencia al tema del ruiseñor en el último epílogo, lo desaconsejan. Tenemos:

$a(202)$ : Voy a contar una fábula a los reyes.

$b$ (203-212): El halcón le dijo al ruiseñor que llevaba en sus garras que por qué gemía: él es más fuerte, le soltará o no según quiera, es insensato oponerse al más poderoso.

$c-a(213-218)$ : Oh Perses, obedece a la Justicia para no sufrir daño, sólo el necio aprende por las consecuencias.

$b$ (219-247): Pues el Juramento y la Justicia persiguen a los perjuros e injustos, también Zeus: para los justos hay abundancia, para los injustos desgracia.

ca (248-251): Oh reyes, cuidáos de la justicia, pues los dioses castigan al injusto.

$b$ (252-262): Hay treinta mil guardianes enviados por Zeus y su hija Justicia sube al Olimpo a denunciarle las injusticias.

$c$ (263-285): Conocedores de esto, reyes, haced justas vuestras palabras. Y tu, Perses, sigue la justicia, pues Zeus se la concedió a los hombres, a diferencia de las bestias: la descendencia del injusto perece, la del justo florece.

El bloque, con toda su mezcla de elementos estructurales, míticos, gnómicos y de las exhortaciones ya a los reyes, ya a Perses, forma un conjunto claro, en torno al tema de la Justicia, propia de los hombres y no de las bestias, defendida por Zeus, el Juramento y la diosa Justicia. Es el cierre, con una extensión e 
intensidad creciente, del tema iniciado tras el proemio: procedimiento de asociación, duplicación e insistencia que nos es ya conocido por Teogonía. Sigue un apéndice que introduce una serie de máximas en cadena. Es el

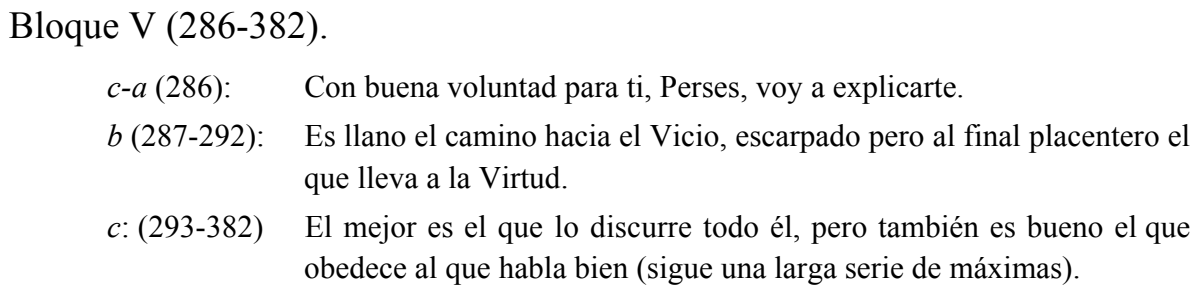

Se trata, ya se ha dicho, de un apéndice al bloque anterior: un segundo elemento $c$ que funciona al tiempo como $a$ para un nuevo pequeño mito, $b$. Pero el cierre que sigue es ya una larga serie de máximas de destinatario general: sólo en 299 se habla de Perses. Ha sido introducida expandiendo un elemento $c$, como algunos bloques eran expandidos, también, en Teogonía mediante aposiciones sucesivas: esta es, naturalmente, diferente.

Pero esta serie de máximas es importante, porque significa una culminación, un cierre, de toda la obra precedente. Para algunos aquí terminaría el poema, lo que sigue serían adiciones posteriores, del propio Hesíodo o no.

Las máximas se refieren fundamentalmente al tema del trabajo y de la riqueza justa obtenida con él: "trabaja, Perses", se dice en 299 y a lo largo de todo el pasaje resuenan palabras con la raíz erg- o erd-, 'trabajar'. Son el Leitmotiv, el hilo conductor, cierto que combinado con otros: ó $\lambda \beta \varsigma$ 'riqueza', $\alpha i \delta \omega ́ \varsigma$ 'respeto', do- 'dar', $\gamma \varepsilon i ́ \tau \omega v$ 'vecino'. Este es el procedimiento de composición asociativa que, de todos modos, es fiel a la intención inicial: "obra así, trabaja trabajo tras trabajo", es el último verso (382).

Así, el tema del hermano, el de los reyes y el de la justicia en conexión con el primero y los segundos, ha ido creciendo gradualmente para combinarse con el del trabajo y dirigirse a todos los hombres. Al final, es esta intención última la que triunfa, el tema del trabajo el que domina. Y justifica la introducción del bloque siguiente, el calendario agrario en cuyo proemio o elemento $a$ se insiste en el tema consabido: "trabaja, necio de Perses" (397). Así, en definitiva, el bloque que estudiamos, fundamentalmente gnómico, hace de transición entre el complejo inicial de mitos y una fábula, con máximas y parénesis entretejidas, 
y el calendario agrícola.

Es, al tiempo, este bloque el clímax de la obra, su culminación. Seguirán luego otros que son meros desarrollos del tema del trabajo o meros apéndices y suplementos. También en esto hay un paralelismo con la Teogonía.

Bloque VI (383-617)

El calendario agrícola está organizado, como ya hemos dicho y como por lo demás es lo habitual en este género literario, en forma cronológica: desde los trabajos de otoño a los de invierno, primavera y verano, para concluir de nuevo en el otoño. Es una cronología que se apoya ya en datos astronómicos sobre la salida o puesta de las constelaciones, ya en otros del mundo animal o vegetal: la migración de las grullas, la llegada de la primavera, el florecimiento del cardo, el canto de la cigarra o del cuco, los movimientos del caracol.

Así se van desarrollando, unas tras otras, las faenas del corte de la leña, la arada y la siembra, la poda de las viñas, la siega, la trilla y recogida de la cosecha, la vendimia. Pero no se trata sólo de descripciones, sino, sobre todo, de exhortaciones y consejos sobre cómo efectuar esas labores. Y no falta el eco del

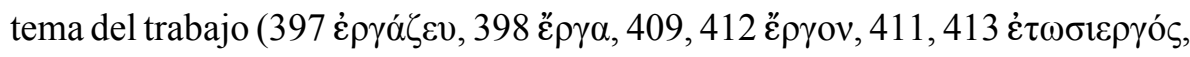

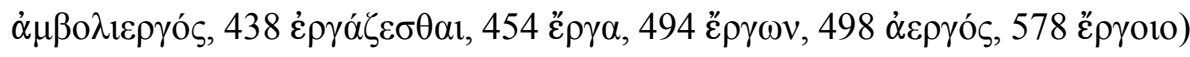
y con él el del ahorro y el de la penuria del hombre que se descuida o no trabaja. Todo esto coloca el calendario agrícola en el ambiente de las partes anteriores.

Ahora bien, intervienen excursos sobre el carácter de las estaciones o sobre la vida del campesino en las mismas. El corte de la leña va seguido de instrucciones para la fabricación del arado (423ss.); la descripción del invierno (493 ss.) va seguida del cuadro de la doncella resguardada en su casa y de consejos sobre el vestido que hay que ponerse; hay la del verano (583 ss.) Y hay intercalación de símiles, máximas, fórmulas, pequeños cuadros y conversaciones (452: diálogo del que pide bueyes prestados y del vecino que se los niega), detalles pintorescos. Todo más o menos próximo al estilo épico, con su abertura, imprevisibilidad y elementos fijos, pero en una versión diferente.

Pero no nos hallamos simplemente ante una organización acumulativa, con excursos y asociaciones: Hesíodo ha hecho un intento para introducir, también aquí, el esquema ternario. De una parte, hay un eco entre el comienzo y el final, con la referencia en ambos lugares a la puesta de las Pléyades y la arada. El fin 
614-617 puede considerarse, así, un epílogo o elemento $c$, que cierra el anillo. Y 383-413 es un proemio o elemento $a$, que contiene los siguientes elementos:

a) Tema de las Pléyades con su orto y ocaso, que señalan respectivamente los puntos culminantes del año agrícola, la siega y la arada, con insistencia a continuación en estos dos temas.

b) Invitación a Perses a que trabaje: es lo que los dioses han asignado a los hombres para que puedan vivir. El pasaje enlaza con la primera parte del poema.

c) Invitación a disponerlo todo (la casa, la mujer, el buey, los instrumentos agrícolas) para el trabajo, con más consejos sobre la diligencia en éste y las malas consecuencias de la pereza.

Es bien claro que en este proemio encontramos una especie de compendio de lo más esencial de lo que va a seguir y de la intención del total.

\section{Bloque VII (618-694)}

Son los trabajos de la navegación, un mero apéndice o complemento al

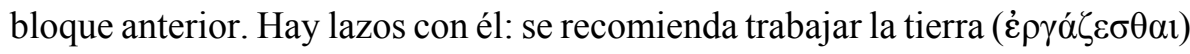
cuando, tras la puesta de las Pléyades, se saca a tierra la nave; se recomienda a Perses hacer los trabajos todos ( $\varepsilon \gamma \gamma \omega v$ ), pero sobre todo los de la mar, en el tiempo debido (641); y retorna una y otra vez el tema biográfico: cómo el padre de Hesíodo y Perses llegó a Ascra desde Cima en Eolia, cómo Hesíodo sólo una vez en su vida se embarcó, cuando fue a Cálcide de Eubea a participar en los Juegos Fúnebres en honor del rey Anfidamante. Hesíodo no recomienda la navegación, pero va a dar instrucciones por si alguien quiere dedicarse a ella.

Hay primero un elemento $a$ o proemio (618-662). El pasaje, tras una introducción sobre el momento de sacar la nave a tierra y el de volver a ponerla a flote, tiene una estructura acumulativa, en que los temas biográficos, propios de los proemios, las máximas y las exhortaciones se mezclan.

El elemento $b$ o centro del bloque (663-693) consiste fundamentalmente en advertencias sobre los riesgos de la navegación, que no debe emprenderse hasta cincuenta días tras el solsticio, ya en Agosto, y una serie de consejos de prudencia, que se resumen en el epílogo $c$ (694): una máxima sobre la medida y la oportunidad.

Bloque VIII (694-764) 
Es una serie de máximas que suplementan a la serie antes vista del bloque V. Como esta serie, enlaza con el bloque anterior: la recomendación de la medida y la oportunidad es continuada por esta otra de tomar mujer $\dot{\omega} \rho \alpha \hat{\imath} o \varsigma$, en la edad adecuada. Se trata, pues, de una continuación del elemento $c$ de VII y, al tiempo, de un suplemento de V.

Contiene, en primer término, consejos positivos sobre la mujer y el matrimonio, los amigos y huéspedes, la conducta: siempre con la vista puesta en la administración de la casa y la prosperidad de vida. Siguen luego prohibiciones, primero del mismo tipo, luego con rasgos que llamaríamos supersticiosos: se prohiben conductas que, tradicionalmente, se considera que traen perjuicio o mala suerte. La organización es puramente acumulativa, asociativa en la

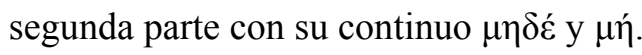

No hay, pues, proemio, hay continuidad inmediata con VII. Pero sí hay un epílogo (c: 960-764) que invita a obrar así y a evitar la mala fama.

\section{Bloque IX (765-828)}

Es el pasaje de "Los días", del que ya hemos hablado y que tantas veces se considera espurio. Hemos presentado su defensa por A. Pérez Jiménez y J. A. Fernández Delgado y a sus trabajos nos referimos para más detalles. Es claro, en todo caso, que el anticlímax de la obra, ya iniciado a partir del bloque VI, el calendario agrícola, llega aquí a su punto más bajo.

El bloque es en realidad un complemento a lo anterior: se trata, en efecto, de señalar qué días son favorables o desfavorables para los diferentes trabajos. Hay un mínimo proemio ( $a$ : "Teniendo cuenta de los días enviados por Zeus") y un epílogo ( $c: 822-828)$ que insiste sobre los días favorables y desfavorables y concluye diciendo: "Feliz y dichoso el que conociendo todas estas propiedades de los días trabaja sin ofender a los inmortales, consultando las aves y evitando las transgresiones". La intención de ligar el bloque al resto del poema es innegable.

La parte central ( $b$ : 766-821) sigue, como es normal, una organización cronológica, bien que con formulaciones cambiantes y con ciertas alteraciones del orden por razones de asociación u otras. Nada nuevo en el panorama de la poesía hesiódica. Para el detalle, envío a los dos trabajos citados.

$\mathrm{Y}$ concluyo haciendo ver que el epílogo $c$ mencionado, aunque referido a 
esta parte, puede considerarse como un cierre de toda la obra, con su insistencia en el tema de trabajo "sin incurrir en culpa para con los dioses". Aunque con alejamiento del tema central de la justicia defendida por Zeus.

\section{El Catálogo de las Mujeres y el Escudo.}

De las demás obras de Hesíodo, las únicas que podemos conocer en cierta medida son el Catálogo de las Mujeres y el Escudo. Aunque ya hemos hablado de los problemas de autenticidad, que se suman al de si los fragmentos editados por West-Merkelbach como pertenecientes a otra obra, las Grandes Eeas, no pertenecerán en realidad a la primera; y el de la relación con la misma del Escudo, cuyo comienzo (1-56) aparece en su fragmento 195 (POxy. 2494 A).

No es este el momento de dilucidar esta cuestión. Y tampoco tenemos datos suficientes, dado el carácter fragmentario de estas obras, para hacer un estudio a fondo de su composición.

Sí es claro que el Catálogo se inicia con un prólogo, que se nos ha transmitido al tiempo como epílogo de Teogonía, ya se dijo. ¿Sería, entonces, nuestro Catálogo un nuevo bloque o conjunto de bloques de esta obra? Y, en este caso, ¿sería un añadido de Hesíodo o de un autor posterior, como se propone?

Nos hallamos, en todo caso, ante poesía genealógica organizada por estirpes (los Eólidas, la descendencia de Inaco, la de Pelasgo, las Atlántides, etc.); dentro de cada una hay un orden cronológico más o menos exacto y hay excursos míticos, de los que conocemos algunos. Pero un grupo de fragmentos como el de 196-204, relativo a los pretendientes de Helena, se sale de esta ordenación: evidentemente, se trataba de un pequeño poema épico-genealógico.

Lo que no vemos clara es la organización interna de los distintos bloques. Ni la de los libros, seguramente cosa de los editores de Alejandría.

El Escudo nos presenta un problema semejante ${ }^{28}$. Aunque inserto, a juzgar por su inicio, en el tema de la descendencia de Alcmena, ha crecido (¿por obra de Hesíodo?) hasta convertirse en un pequeño poema épico, con todas las características de éstos. En realidad, sólo lo que es el primer proemio de nuestro

28 Cf. A. Pérez Jiménez y A. Martínez Díaz, Hesíodo. Obras y Fragmentos, Madrid, 1978, p. 269 ss., con bibliografía. 
Escudo, que se corresponde con la parte transmitida parcialmente por el papiro del Catálogo, parece realmente adecuado a él: se trata de Alcmena y de cómo concibió a sus dos hijos Heracles e Ificles por obra, respectivamente, de Zeus y Anfitrión.

Pero en nuestro Escudo de transmisión manuscrita todo esto no es sino el proemio de la narración (57-466); el final (467-480), el entierro de Cicno, puede considerarse como el epílogo o elemento $c$.

La narración épica se desarrolla conforme a los modelos tradicionales, aunque con excesivo énfasis en la descripción del escudo que la diosa Atena llevó (como Tetis a Aquiles, hay una clara imitación) a su protegido Heracles para que luchara con el monstruoso Cicno, hijo de Ares. Contiene, fundamentalmente, los siguientes elementos:

57-76: anticipo sobre la hazaña de Heracles (segundo proemio).

77-121: diálogo entre Heracles y su auriga Iolao, al que incita a la lucha.

122-324: armadura de Heracles y extensa descripción del escudo.

325-344: palabra de Atena a Heracles, dándole instrucciones para la lucha.

344-367: diálogo de Heracles y Cicno.

368-423: primer combate, Heracles mata a Cicno.

424-466: segundo combate, Atena salva a Heracles, éste hiere a Ares, a quien sus servidores se llevan al Olimpo.

Son todos, ya digo, elementos tradicionales. En realidad, se trata de un epilio cerrado, con su proemio 57-76 y su epílogo, ya mencionado, 467-480: pero el total ha sido añadido como un conjunto al relato sobre la de descendencia de Alcmena.

Sea Hesíodo o no sea Hesíodo el autor de esta adición, parece claro que esta expansión del tema de Héracles, hijo de Zeus y vencedor de monstruos, se consideró adecuada dentro del contexto de alabanza de Zeus y de su hijo (cf. supra sobre su papel en Teogonía) en la obra del poeta de Ascra. 